\title{
Modified Food Selection Improves Obesity-Related Metabolic Distur- bances Independent from Weight Loss
}

\author{
Lena Håglin*, Sara Lundström and Lennart Bäckman
}

Department of Public Health and Clinical Medicine, Family Medicine, Umeå University, 90187 Umeå, Sweden

\begin{abstract}
Dietary therapy has been shown to be important to reduce weight and other risk factors for CVD if a high-risk pattern is present. We investigated if modified food selection improved obesity-related metabolic disturbance independently from weight loss in a prospective cohort study. After a comprehensive 4-week residential period which stressed healthy food, physical training, and stress management, patients were followed for one year. The most common diagnoses besides obesity were hypertension, type- 2 diabetes and dyslipidemia. A dietary questionnaire was completed at the first visit and after one year. Weight loss resulted in lower blood glucose (B-Glu) Odds Ratio (OR) $=2.45, p<0.001$, serum triglyceride $(\mathrm{S}-\mathrm{TG}) \mathrm{OR}=2.80, p<0.001$ and serum urate $(\mathrm{S}$-Urate) $\mathrm{OR}=2.62, p<0.001$. With less fat on bread body weight was reduced $(\mathrm{OR}=2.46, p<0.01)$, and with less candy $\mathrm{S}$-HDL was increased $(\mathrm{OR}=1.72, p<0.01)$ and $\mathrm{S}$-Urate was decreased $(\mathrm{OR}=2.10, p<0.001)$. A decrease in S-Urate was not found associated with more fruit and berries $(\mathrm{OR}=0.48$ $p<0.05)$, less cheese $(\mathrm{OR}=0.38, p<0.05)$ or less milk $(\mathrm{OR}=0.50 p<0.05)$. Less coffee was associated with decreased systolic blood pressure $(\mathrm{SBP}) \mathrm{OR}=1.85, p<0.05$. Modified food selection was associated with improved risk factor levels independently from weight loss.
\end{abstract}

Keywords: Food, intervention, metabolic syndrome, obesity, weight loss.

\section{INTRODUCTION}

To improve health - e.g., by tackling the increasing problem of obesity and related metabolic disorders -- risk factors can be reduced by making changes in food consumption, both amount and type, and by increasing physical activity [14]. Lifestyle interventions have strong impact on CVD risk factors [1, 2, 5-7]. A combination of dietary changes, energy restriction and increased level of physical activity seems to be effective in the long run, and often more pronounced in the short term $[8,9]$.

During recent years the influence from macronutrients, e.g., high protein or high carbohydrate diets, has been in focus for weight loss and CVD risk factors. Both high carbohydrate and high protein diets improve CVD risk with weight loss, although the weight loss per se causes these improvements [10]. Comparable effects on long-term weight loss may be achieved with diets differing in glycemic load $[11,12]$.

The DASH diet reduces blood pressure and modifies biomarkers of disease risk [2]. Exercise and healthy diet are known to improve carbohydrate metabolism and glycemic control $[13,14]$. Also, energy restriction with body weight loss improves glycemic control in obesity and mild type-2 diabetes [15]. Obesity-related disturbances are thus alleviated by reducing body weight [16]. However, there is an increasing interest in the effects of different types of diets and food groups, a complement to the focus on single macronutrients [17-19]. Protective effects from whole-grain,

*Address correspondence to this author at the Department of Public Health and Clinical Medicine, Family Medicine, University Hospital, Umeå, SE90185 UMEÅ, Sweden; Tel: +46 (0) 9078523 32; Fax: +46 (0) 901379 19; E-mail: lena.haglin@vll.se low-fat dairy products, vegetables, and fruit have been presented [20-23]. This study assessed whether a modification in the selection of single foods could be associated with improvements in obesity-related disturbances after adjusting for weight loss, sex and age one year after a 4-week comprehensive intervention program.

\section{MATERIALS AND METHODOLOGY}

\section{Population and Intervention}

Patients ( $\mathrm{n}=995)$ were referred during 1984-1987, from physicians working in primary health care and in hospitals in Västerbotten, Sweden to the Vindeln Patient Education Center (VPE-center). They had multiple health problems, e.g., hypertension, type- 2 diabetes and dyslipidemia, in addition to obesity [24]. No differences in mean body weight or level of metabolic disturbance were seen at the baseline between the study group $(n=599)$ and those subjects who did not accept the invitation $(n=396)$ after one year. To be included, they had to be physically able to take part in a full-time schedule. The 4-week residential comprehensive program consisted of group sessions that addressed nutrition, physical activities, stress relief, smoking cessation, etc. [25]. A dietician, a physician, and a physiotherapist gave individualized advice about energy restriction and physical training at the end of the course at the Centre, to be maintained in the habitual environment. Daily energy intake was restricted to $6,000-7500 \mathrm{~kJ}(\sim 1,500 \mathrm{kcal})$ per day, achieved by prescribing a diet with a low-fat content and a low energy density. The goals for this study were to assess the associations between patterns of food selection and metabolic parameters related to obesity at admittance and after one year. Patients were invited to a four-day refresher course after one year to remind them about the importance of addressing lifestyle with both proper food choices and physical activity. 


\section{Physical and Biochemical Variables}

The physical examination was performed on the first or second day of the visit. A medical journal was set up for each patient admitted, and all data, including for the followup period, were collected at the Centre. The BMI $\left(\mathrm{kg} / \mathrm{m}^{2}\right)$ was calculated, and systolic blood pressure (SBP) and diastolic blood pressure (DBP) ( $\mathrm{mmHg}$ ) were measured as a mean of three BP measurements obtained in a sitting position.

At the start of the program, all patients fasted before blood samples were drawn in the morning. The samples were analyzed according to standardized routine procedures of the Department of Clinical Chemistry, University Hospital, Umeå, Sweden. The levels of B-Glu (mmol/l), S-TG $(\mathrm{mmol} / \mathrm{l})$, S-Chol $(\mathrm{mmol} / \mathrm{l})$, S-HDL $(\mathrm{mmol} / \mathrm{l})$, and S-Urate $(\mathrm{mmol} / \mathrm{l})$ were determined using routine methods on a Hitachi 717 multianalyser (Boehringer Mannheim Diagnostica, Mannheim, Germany).

\section{Food Questionnaire and Selections}

When the patients were admitted to the VPE Center, questionnaires (995) were used to gather information about their selection of raw vegetables (frequency), fruit and berries (frequency), milk (frequency and type), cheese (frequency), candies (frequency), fat (amount and type), bread (type), coffee (cups), sugar in coffee or tea (lumps), salt (fre- quency), cookies and cakes (frequency). Patients completed questionnaires again at the 4-day follow-up a year later $(\mathrm{n}=599,60 \%)$.

Questions about time spent eating and smoking habits were also evaluated (data not presented in this report). An individual patient could have changed in one or more of 14 dietary questions, but a healthy choice in one question did not necessarily indicate a healthy choice in another question. A healthy food selection corresponded to more raw vegetables, fruit and berries, whole-grain bread, low-fat margarine, less full-cream milk or less amount of milk, fat on bread, candy, sugar in coffee, cookies and cakes, table salt, coffee, and alcoholic beverages.

\section{Statistics}

Multiple logistic regression analysis, with changed risk factor level over one year as dependent variables, was performed and adjusted ORs (95\% CI) were calculated for food choices and alcohol intake over one year. Each model was adjusted for baseline pattern for the food selected (dichotomized), age, sex, BMI at baseline, BMI change and baseline value for the risk factor studied. For S-HDL, baseline cholesterol change in S-Chol was included.

The analyses were carried out using the SAS program pack 9.1.3 [26]. Proc GLM in the SAS program was used. Multiple comparisons were made using the Bonferroni

Table 1. Personal Data, Risk Factors and Main Diagnoses for the whole Cohort and Study Group and for the Subjects Not Admitted to the Follow Up. DM = Diabetes Mellitus. IHD/PMI = Ischemic Heart Disease/Post-Myocardial Infarction

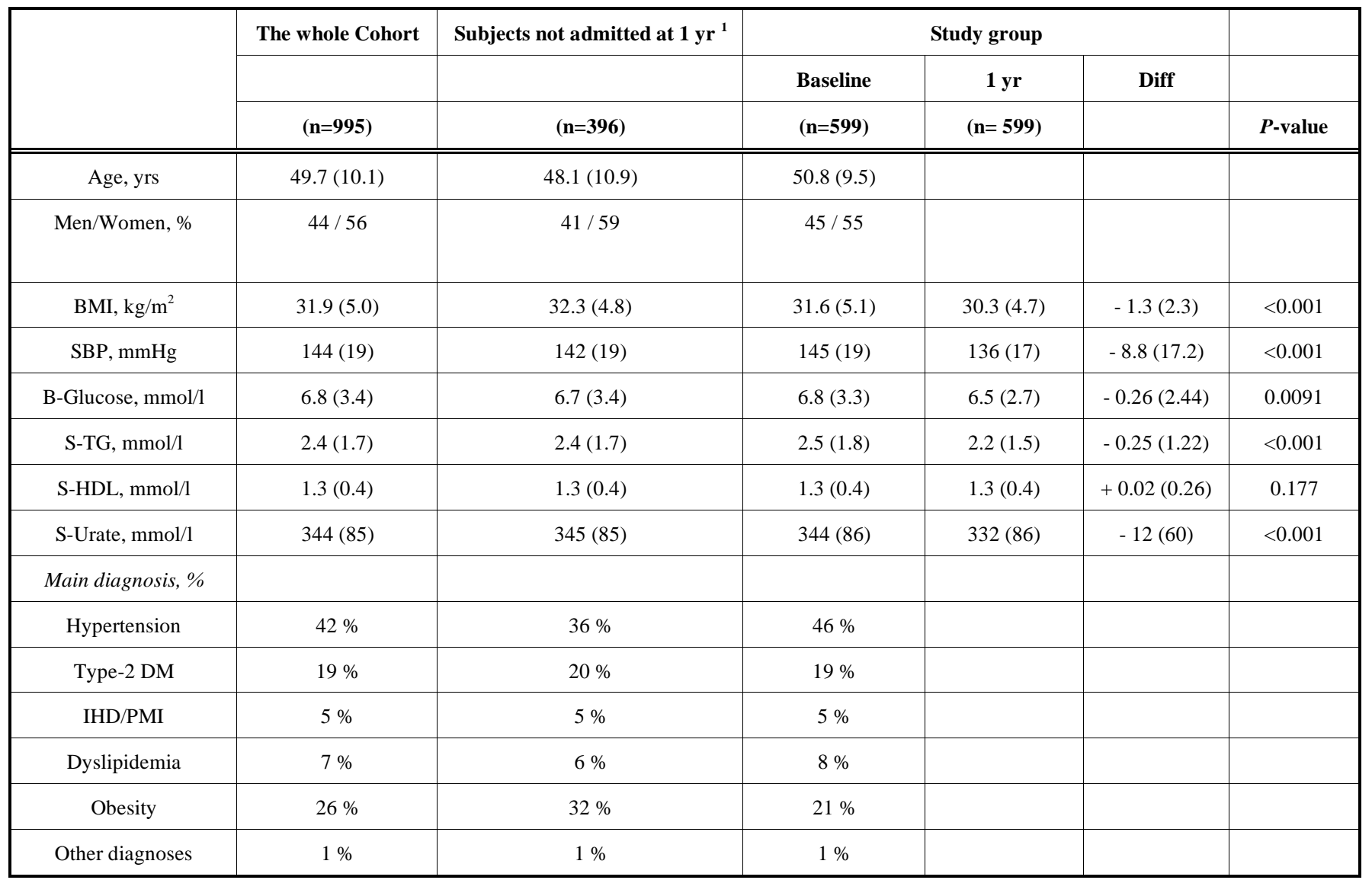

All values are mean and (SD).

${ }^{1}$ Values are not significantly different from that of the study group at baseline. 
method [27]. In the multiple regressions, age, sex, and BMI at baseline and changes in BMI over one year together with the level of the metabolites at baseline were controlled for. Adjustments were also made for the baseline food selection. Each question was coded and turned into indicator variables. Data that were lacking in the questionnaires were considered as missing. The study was approved by the Regional Ethical Review Board in Umeå, Sweden (Dnr 05-177M) and registered as a Lifestyle intervention trial (no. ISRCTN79355192).

\section{RESULTS}

\section{Patients and Diagnoses}

The change in level of metabolites at one year was compared to the baseline for each individual, and thereby each patient acted as his or her own control (Table 1). One fifth of the study group had obesity as the main diagnosis and they had a low prevalence of an additional diagnosis (Table 1). The aim with the therapy in this group was to prevent the progression of metabolic disturbance associated with obesity. Body mass index $\left(B M I=\mathrm{kg} / \mathrm{m}^{2}\right)$ in this group at the time of admission $\left(35.1 \pm 4.7 \mathrm{~kg} / \mathrm{m}^{2}\right)$ was also higher than in subjects with type- 2 diabetes $(30.4 \pm 4.9 ; p<0.001)$ or hypertension $(31.5 \pm 5.2 ; p<0.001)$.

\section{Body Weight Loss}

Mean body weight loss at one year was $4.0 \pm 5.8 \mathrm{~kg}$ (BMI change $=-1.3 \pm 2.3$ ), a number that corresponds to $4.2 \pm 5.7 \%$ of initial body weight. Women lost $4.1 \pm 6.1 \mathrm{~kg}(3.7 \pm 6.0 \%)$ and men $4.4 \pm 5.5 \mathrm{~kg}(4.3 \pm 5.2 \%)$.

The difference for each metabolite over one year is presented in Table 1. The multiple logistic regression analysis with BMI change as the dependent variable and each of the risk factors as the independent variables with adjustments for age, sex, BMI and the risk factor at baseline are presented in Table 2. There was a high correlation between the level of the metabolites at baseline and its change over time. These correlations are referred to as regression towards the mean. Age and sex were also associated with a change in S-Urate.

\section{Modified Food Selection}

To evaluate effects of food selection on changes in obesity-related metabolic variables, each risk factor change was used as the dependent variable with age and sex, BMI at baseline, change in BMI and baseline-values for every single metabolite and food pattern included as independent variables in each model.

As seen in Table $\mathbf{3}$, using less fat on bread was associated with weight loss $(\mathrm{OR}=2.461 \quad(1.378-4.395)(p<0.01)$. Eating more whole-grain bread and more vegetables was almost significantly associated with weight loss $(\mathrm{OR}=1.746(0.977$ $3.121)(p<0.06)$ and $1.681(0.933-3.030)(p<0.08)$, respectively. A reduction in coffee consumption (reduced from $>7$ cups a day) reduced SBP. More vegetables but not less cookies and cakes reduced S-TG. Less fat on bread, increased intake of low-fat margarine/improved fat quality or less candy increased S-HDL. More fruit and berries, less milk or cheese limited the possibility to reduce S-Urate. A decreased frequency of candy or alcohol decreased S-Urate.

\section{DISCUSSION}

A weight loss of $4-5 \mathrm{~kg}$, or about $4 \%$ of the initial body weight, was associated with decreased B-Glu, S-TG, and SUrate levels after adjustment for age, sex and BMI. With this moderate weight loss, important improvements of CVD risk factors were still shown. The impressive decrease of SBP ($8.8 \mathrm{mmHg}$ ) indicates the importance of multiple lifestyle interventions. However, exercise and diet-induced weight loss may be additive in the effect on high blood pressure [1].

Other lifestyle intervention trials show reduced SBP and blood lipids at a weight loss between 5 and $10 \%$ of the baseline weight $[28,29]$. The metabolic response per se from a negative energy balance seems to be important, rather than the level of weight loss or the glycemic load [11]. Weight loss elicits physiological improvements - making it difficult to conclude about the effects from macronutrients and/or different food items.

We performed a multiple logistic regression analysis to control for weight loss in the test of associations between altered food selection and obesity-related disturbances. The strength of each change, e.g., the level of risk besides age and sex, and progression of the disease, has to be considered to understand the effect of dietary changes on obesity-related disturbances.

Other intervention studies, which focus on multiple lifestyle changes, show similar results to those in our study [5-7, 16]. Even greater effects have been shown 6 months after a lifestyle intervention with a loss of $8 \%$ of body weight and $10 \mathrm{mmHg}$ decreases in SBP [8]. A weight loss of $4 \%$ was achieved in addition to improved cardiovascular function

Table 2. The Association Between Weight Change and Changes in Risk Factors Over One Year

\begin{tabular}{|c|c|c|c|}
\hline Variables & n & OR (95\% CI) & P-value \\
\hline \hline SBP, $\mathrm{mmHg} \downarrow$ & 567 & $1.331(0.811-2.182)$ & 0.2577 \\
\hline B-Glu, $\mathrm{mmol} / \mathrm{l} \downarrow$ & 498 & $2.452(1.495-4.021)$ & 0.0004 \\
\hline $\mathrm{S}-\mathrm{TG}, \mathrm{mmol} / \mathrm{l} \downarrow$ & 555 & $2.804(1.759-4.469)$ & 0.0001 \\
\hline S-Chol, $\mathrm{mmol} / \mathrm{l} \downarrow$ & 563 & $1.271(0.803-2.011)$ & 0.3067 \\
\hline S-HDL, $\mathrm{mmol} / \mathrm{l} \uparrow$ & 558 & $1.366(0.865-2.159)$ & $<0.0001$ \\
\hline S-Urate, $\mathrm{mmol} / \mathrm{l} \downarrow$ & 550 & $2.615(1.630-4.196)$ & $<$ \\
\hline
\end{tabular}

Each calculation was adjusted for age, sex, BMI and the risk factor at baseline. For S-HDL, S-Chol at baseline and change over one year are included. 
Table 3. Association Between Changed Risk Factor Levels (Dependent Variables) and Altered Food Selection

\begin{tabular}{|c|c|c|c|c|c|c|c|}
\hline Changed pattern & $\mathbf{N}$ & BMI $\left(\mathrm{kg} / \mathrm{m}^{2}\right)$ & SBP (mmHg) & B-Glu (mmol/l) & S-TG $(\mathrm{mmol} / \mathrm{l})$ & S-HDL (mmol/li) & $\begin{array}{l}\text { S-Urate } \\
(\mathrm{mmol} / \mathrm{l})\end{array}$ \\
\hline & & $\downarrow$ & $\downarrow$ & $\downarrow$ & $\downarrow$ & $\uparrow$ & $\downarrow$ \\
\hline Raw vegetables $\uparrow$ & 539 & $\begin{array}{c}1.681 \\
0.933-3.030\end{array}$ & $\begin{array}{c}0.792 \\
0.471-1.330\end{array}$ & $\begin{array}{c}0.757 \\
0.465-1.233\end{array}$ & $\begin{array}{c}1.650^{*} \\
1.003-2.714\end{array}$ & $\begin{array}{c}1.019 \\
0.640-1.622\end{array}$ & $\begin{array}{c}1.338 \\
0.829-2.160\end{array}$ \\
\hline $\begin{array}{c}\text { Fruit and berries } \\
\uparrow\end{array}$ & 551 & $\begin{array}{c}0.772 \\
0.369-1.616\end{array}$ & $\begin{array}{c}1.001 \\
0.530-1.890\end{array}$ & $\begin{array}{c}0.806 \\
0.429-1.514\end{array}$ & $\begin{array}{c}0.616 \\
0.329-1.154\end{array}$ & $\begin{array}{c}0.873 \\
0.486-1.567\end{array}$ & $\begin{array}{c}0.482^{*} \\
0.262-0.887\end{array}$ \\
\hline Amount of milk $\downarrow$ & 526 & $\begin{array}{c}0.847 \\
0427-1.682\end{array}$ & $\begin{array}{c}1.803 \\
0.990-3.285\end{array}$ & $\begin{array}{c}0.720 \\
0.401-1.293\end{array}$ & $\begin{array}{c}0.929 \\
0.521-1.657\end{array}$ & $\begin{array}{c}1.350 \\
0.780-2.335\end{array}$ & $\begin{array}{c}0.501^{*} \\
0.284-0.884\end{array}$ \\
\hline Full-cream milk $\downarrow$ & 525 & $\begin{array}{c}1.325 \\
0.757-2.318\end{array}$ & $\begin{array}{c}0.798 \\
0.486-1.310\end{array}$ & $\begin{array}{c}1.297 \\
0.800-2.104\end{array}$ & $\begin{array}{c}1.282 \\
0.794-2.070\end{array}$ & $\begin{array}{c}1.080 \\
0.690-1.690\end{array}$ & $\begin{array}{c}0.938 \\
0.590-1.491\end{array}$ \\
\hline $\begin{array}{c}\text { Amount of cheese } \\
\downarrow\end{array}$ & 485 & $\begin{array}{c}1.061 \\
0.487-2.310\end{array}$ & $\begin{array}{c}1.169 \\
0.617-2.216\end{array}$ & $\begin{array}{c}1.038 \\
0.567-1.900\end{array}$ & $\begin{array}{c}1.052 \\
0.569-1.944\end{array}$ & $\begin{array}{c}1.298 \\
0.732-2.304\end{array}$ & $\begin{array}{c}0.383^{*} \\
0.205-0.717\end{array}$ \\
\hline $\begin{array}{c}\text { Whole-grain } \\
\text { bread } \uparrow\end{array}$ & 493 & $\begin{array}{c}1.746 \\
0.977-3.121\end{array}$ & $\begin{array}{c}1.033 \\
0.616-1.731\end{array}$ & $\begin{array}{c}1.242 \\
0.770-2.004\end{array}$ & $\begin{array}{c}1.186 \\
0.730-1.928\end{array}$ & $\begin{array}{c}1.088 \\
0.691-1.713\end{array}$ & $\begin{array}{c}1.203 \\
0.748-1.934\end{array}$ \\
\hline Fat on bread $\downarrow$ & 483 & $\begin{array}{c}2.461^{* *} \\
1.378-4.395\end{array}$ & $\begin{array}{c}1.228 \\
0.763-1.977\end{array}$ & $\begin{array}{c}0.738 \\
0.471-1.156\end{array}$ & $\begin{array}{c}1.394 \\
0.873-2.227\end{array}$ & $\begin{array}{c}1.581^{*} \\
1.032-2.424\end{array}$ & $\begin{array}{c}1.128 \\
0.724-1.756\end{array}$ \\
\hline $\begin{array}{l}\text { Low-fat marga- } \\
\text { rine } \uparrow\end{array}$ & 503 & $\begin{array}{c}1.471 \\
0.848-2.552\end{array}$ & $\begin{array}{c}0.681 \\
0.425-1.091\end{array}$ & $\begin{array}{c}0.845 \\
0.531-1.344\end{array}$ & $\begin{array}{c}1.111 \\
0.703-1.755\end{array}$ & $\begin{array}{c}1.655^{*} \\
1.070-2.558\end{array}$ & $\begin{array}{c}1.203 \\
0.769-1.881\end{array}$ \\
\hline Candies $\downarrow$ & 516 & $\begin{array}{c}1.099 \\
0.645-1.872\end{array}$ & $\begin{array}{c}0.955 \\
0.603-1.511\end{array}$ & $\begin{array}{c}1.155 \\
0.740-1.803\end{array}$ & $\begin{array}{c}0.850 \\
0.549-1.317\end{array}$ & $\begin{array}{c}1.722^{* * *} \\
1.131-2.622\end{array}$ & $\begin{array}{c}2.099^{* * * *} \\
1.349-3.265\end{array}$ \\
\hline Sugar in coffee $\downarrow$ & 553 & $\begin{array}{c}0.925 \\
0.426-2.012\end{array}$ & $\begin{array}{c}0.798 \\
0.393-1.620\end{array}$ & $\begin{array}{c}0.799 \\
0.399-1.601\end{array}$ & $\begin{array}{c}0.584 \\
0.288-1.185\end{array}$ & $\begin{array}{c}1.112 \\
0.577-2.141\end{array}$ & $\begin{array}{c}0.636 \\
0.326-1.243\end{array}$ \\
\hline $\begin{array}{c}\text { Cookies and } \\
\text { cakes } \downarrow\end{array}$ & 511 & $\begin{array}{c}1.292 \\
0.788-2.118\end{array}$ & $\begin{array}{c}0.716 \\
0.462-1.109\end{array}$ & $\begin{array}{c}1.063 \\
0.698-1.618\end{array}$ & $\begin{array}{c}0.639^{*} \\
0.418-0.976\end{array}$ & $\begin{array}{c}1.090 \\
0.735-1.618\end{array}$ & $\begin{array}{c}1.221 \\
0.811-1.837 \\
\end{array}$ \\
\hline Table salt $\downarrow$ & 527 & $\begin{array}{c}1.351 \\
0.722-2.529\end{array}$ & $\begin{array}{c}1.423 \\
0.811-2.495\end{array}$ & $\begin{array}{c}0.731 \\
0.426-1.256\end{array}$ & $\begin{array}{c}0.863 \\
0.503-1.481\end{array}$ & $\begin{array}{c}1.070 \\
0.648-1.767\end{array}$ & $\begin{array}{c}0.884 \\
0.523-1.496\end{array}$ \\
\hline Coffee $\downarrow$ & 522 & $\begin{array}{c}0.895 \\
0.473-1.695\end{array}$ & $\begin{array}{c}1.851^{*} \\
1.017-3.372\end{array}$ & $\begin{array}{c}1.670 \\
0.958-2.912\end{array}$ & $\begin{array}{c}0.782 \\
0.455-1.342\end{array}$ & $\begin{array}{c}0.783 \\
0.472-1.300\end{array}$ & $\begin{array}{c}1.141 \\
0.667-1.953\end{array}$ \\
\hline Alcohol $\downarrow$ & 505 & $\begin{array}{c}0.833 \\
0.480-1.447\end{array}$ & $\begin{array}{c}1.511 \\
0.907-2.519\end{array}$ & $\begin{array}{c}1.084 \\
0.671-1.752\end{array}$ & $\begin{array}{c}1.239 \\
0.770-1.994\end{array}$ & $\begin{array}{c}1.405 \\
0.893-2.211\end{array}$ & $\begin{array}{c}1.645^{*} \\
1.026-2.640\end{array}$ \\
\hline
\end{tabular}

Each calculation was adjusted for baseline pattern of the variable, age, sex, BMI at baseline, BMI change and baseline value for the risk factor studied. For S-HDL, baseline cholesterol and change in S-Chol was included. $p<0.05^{* * *} p<0.01{ }^{* * * *} p<0.001$.

already after two months [9]. After 14 months, moderately low-fat intake, rather than very low fat intake, improved CVD risk factors, and this could be explained by better adherence to the dietary strategies [30]. In our study a reduced amount of fat on bread, indicating less energy density of the diet, was associated with weight loss and increased S-HDL. Whole-grain cereals can reduce the risk of type-2 DM [31] and reduce visceral adipose tissue [20]. Both of those effects of whole-grain cereals, blood glucose reduction and body weight loss, may reduce the risk of developing type-2 DM. However, in our study we did not find any effect of increased intake of whole-grain bread on the studied CVD risk factors.

Modified food selection and increased physical training were the main goals at the VPE-center. It has been shown that low fat milk intake may prevent insulin resistance syndrome [21]. It has also been shown in the DASH study that a low fat diet, besides salt restriction and intake of low-fat milk products, reduces BP $[2,32]$. However, changing from high fat to low-fat milk in the present study did not reduce body weight or any of the risk factors studied. On the contrary, we found that a reduced milk intake hindered a decrease in S-Urate. This suggests that further studies are needed on the effect of milk intake on CVD risk factors. The most impressive BP reductions in the present study were seen with a reduced alcohol intake $(12.5 \pm 17.6 \mathrm{mmHg}) . \mathrm{Nu}-$ merous dietary factors can influence $\mathrm{BP}[2,32,33]$. By reducing alcohol in the obese, high-risk condition, we found a decreased S-TG and an almost significant decrease in SBP and S-Urate after adjusting for weight loss and other confounders. Weight loss and reduced alcohol intake are two therapeutic goals in treating patients with gout, and these results are of interest also in the obese condition. Because $\mathrm{S}$ Urate is a risk factor for morbidity and mortality (especially 
in metabolic syndrome), and because weight loss and changed food selection (more fruit, less candy, less alcohol) can influence the degree of S-Urate reduction, these results need to be evaluated further. S-Urate should then be considered either as an end product from purine metabolism or as an antioxidant. More fruit and vegetables are described as one way to improve health [34]. We found that an increased intake of fruit and berries was less likely to be associated with a decrease in S-Urate levels. It is shown that S-Urate increases with a high consumption of apples, six per day [35]. As fruit is more frequently consumed than berries, and since fruit contains more fructose than berries, we think the changes in S-Urate may have been due to changes in fruit intake. However, no studies have investigated this question. Thus, it seems to be important to study the effects of vegetables separated from those of fruit when S-Urate is evaluated in connection with obesity. Due to the recommendations to increase intake of whole-grain bread, fruit and vegetables, the carbohydrate intake was probably increased. Portion sizes of meat, fish and chicken, etc. were kept normal and therefore, the protein intake was probably reduced and the relative contributions of protein and carbohydrates (P/CHOratio) was probably also reduced after the intervention.

It is well known that obesity is positively related to S-TG and inversely related to S-HDL [36]. As S-HDL levels are associated with both age and sex, this could have contributed to the lesser influence of dietary changes on S-HDL. By reducing amount of candy and fat on bread, but also improving fat quality, S-HDL will increase. It has been shown in another study that nutrition education and dietary counselling strategies, in addition to physical activity prescription, should be followed-up closely to maintain increased S-HDL and decreased S-TG levels [37]. Katan et al. (1997) discussed whether a high carbohydrate diet should be recommended for everyone, due to the fact that S-TG might increase and S-HDL decrease with such a diet [38].

The dietary treatment offered at VPE-Center had impressive effects on obesity-related metabolic disturbances over one year, and improved metabolic profiles were associated with changed selections for a healthy food pattern. More vegetables, less fat on bread, more whole-grain bread, and less candy are all important recommendations to achieve benefits. The question about the amount of fruit in a weightloss regime needs to be studied further in both clinical and epidemiological studies, but the advice to reduce alcohol seems to be effective. The importance of improved selections of food, to choose "the healthy alternatives", is necessary for improving obesity related disturbances.

\section{CONCLUSION}

The multiple logistic regressions showed that improved food selection was associated with weight loss and improved obesity-related risk factors for CVD. Furthermore, the improved risk factors occurred independently from the weight loss. Both a reduction of candy and increased intake of fruit and berries contributed to a change in S-Urate, but in opposite directions. With improved fat quality, less fat on bread and less candy, S-HDL increased.

\section{REFERENCES}

[1] Gordon NF, Scott CB, Levine BD. Comparison of single versus multiple lifestyle interventions: are the antihypertensive effects of exercise training and diet-induced weight loss additive? Am J Cardiol 1997; 79: 763-7.

[2] Blumenthal JA, Babyak MA, Hinderliter A, et al. Effects of the DASH diet alone and in combination with exercise and weight loss on blood pressure and cardiovascular biomarkers in men and women with high blood pressure: the ENCORE study. Arch Intern Med 2010; 170: 126-35.

[3] Stamler J, Dolecek TA. Relation of food and nutrient intakes to body mass in the special intervention and usual care groups in the Multiple Risk Factor Intervention Trial. Am J Clin Nutr 1997; 65: 366S-73S.

[4] Fox AA, Thompson JL, Butterfield GE, Gylfadottir U, Moynihan S, Spiller G. Effects of diet and exercise on common cardiovascular disease risk factors in moderately obese older women. Am J Clin Nutr 1996; 63: 225-33.

[5] Ornish D, Scherwitz LW, Billings JH, et al. Intensive lifestyle changes for reversal of coronary heart disease. J Am Med Assoc 1998; 280: 2001-7.

[6] Gaede P, Vedel P, Larsen N, et al. Multifactorial intervention and cardiovascular disease in patients with type 2 diabetes. N Engl J Med 2003; 348: 383-93.

[7] Kim SH, Lee SJ, Kang ES, et al. Effects of lifestyle modification on metabolic parameters and carotid intima-media thickness in patients with type 2 diabetes mellitus. Metab Clin Exp 2006; 55: 1053-9.

[8] Villareal DT, Miller BV, Banks M, Fontana L, Sinacore DR, Klein S. Effect of lifestyle intervention on metabolic coronary heart disease risk factors in obese older adults. Am J Clin Nutr 2006; 84: 1317-23.

[9] Wong CY Byrne NM, O'Moore-Sullivan T, et al. Effect of weight loss due to lifestyle intervention on subclinical cardiovascular dysfunction in obesity (Body Mass Index $>30 \mathrm{~kg} / \mathrm{m}^{2}$ ). Am J Cardiol 2006; 98: 1593-8.

[10] Noakes M, Keogh JB, Foster PR, Clifton PM. Effect of an energyrestricted, high-protein, low-fat diet relative to a conventional highcarbohydrate, low-fat diet on weight loss, body composition, nutritional status, and markers of cardiovascular health in obese women. Am J Clin Nutr 2005; 81: 1298-1306.

[11] Das SK, Gilhooly CH, Golden JK, et al. Long-term effects of 2 energy-restricted diets differing in glycemic load on dietary adherence, body composition, and metabolism in CALERIE: a 1-y randomized controlled trial. Am J Clin Nutr 2007; 85: 1023-30.

[12] Periera MA, Swain J, Goldfine AB, Rifai N, Ludwig DS. Effects of a low-glycemic load diet on resting energy expenditure and heart disease risk factors during weight loss. J Am Med Assoc 2004; 292: 2482-90.

[13] Anderssen SA, Hjermann I, Urdal P, et al. Improved carbohydrate metabolism after physical training and dietary intervention in individuals with the "atherothrombogenic syndrome". Oslo Diet and Exercise Study (ODES). A randomized trial. J Intern Med 1996; 240: 203-9.

[14] Krook A, Holm I, Pettersson S, Wallberg-Henriksson H. Reduction of risk factors following lifestyle modification programme in subjects with type 2 (non-insulin dependent) diabetes mellitus. Clin Physiol Funct Imaging 2003; 23: 21-30.

[15] Markovic TP, Jenkins AB, Campbell LV. The determinants of glycemic responses to diet restriction and weight loss in obesity and NIDDM. Diabetes Care 1998; 21: 687-94.

[16] Andersson K, Karlström B, Fredén S, Peterson H, Öhrvall M, Zethelius B. A two-year clinical lifestyle intervention program for weight loss in obesity. Food Nutr Res 2008; 52: 10.3402/fnr.v52i0.1656.

[17] Joshipura KJ, Frank B, Manson JE, et al. The effect of fruit and vegetable intake on risk for coronary heart disease. Ann Intern Med 2001; 134: 1106-14.

[18] Chahoud G, Aude W, Mehta JL. Dietary recommendations in the prevention and treatment of coronary heart disease: Do we have the ideal diet yet? Am J Cardiol 2004; 94: 1260-1267.

[19] Hu FB, Rimm EB, Stampfer MJ. Prospective study of major dietary patterns and risk of coronary heart disease in men. Am J Clin Nutr 2000; 72: 912-21.

[20] McKeown NM, Troy LM, Jacques PF, Hoffmann U, O'Donnell CJ, Fox CS. Whole- and refined-grain intakes are differentially associated with abdominal visceral and subcutaneous adiposity in healthy adults: the Framingham Heart Study. Am J Clin Nutr 2010; 92: 1165-71. 
[21] Tremblay A, Gilbert JA. Milk products, insulin resistance syndrome and type 2 diabetes. J Am Coll Nutr 2009; Suppl 1: 91S$102 \mathrm{~S}$.

[22] Bray GA, Ryan DH, Harsha DW. Diet, weight loss and cardiovascular disease prevention. Curr Treat Opt Cardiovasc Med 2003; 5: 259-69.

[23] Newby PK, Muller D, Hallfrisch J, Qiao N, Andres R, Tucker KL. Dietary patterns and changes in body mass index and waist circumference in adults. Am J Clin Nutr 2003; 77: 1417-25.

[24] Håglin L, Lundström S, Kaati G, Bäckman L, Bygren LO. Allcause mortality of patients with dyslipidemia up to 19 years after a multidisciplinary lifestyle modification programme: a randomized trial. Eur J Cardiovasc Prev Rehabil. 2010 Aug 7. [Epub ahead of print].

[25] Sjöström M, Karlsson AB, Kaati G, Yngve A, Green LW, Bygren LO. A four week residential program for primary health care patients to control obesity and related heart risk factors: effective application of principles of learning and lifestyle change. Eur J Clin Nutr 1999; 53(Suppl 2): S72-7.

[26] SAS/STAT Guide for Personal Computers, Version 6 edition, SAS Institute Inc.

[27] Neter J, Wasserman W, Kutner MH. Applied Linear Regression Models. IRWIN Homewood, Illinois 1983.

[28] Miller ER 3rd, Erlinger TP, Young DR, et al. Results of the Diet, Exercise, and Weight Loss Intervention Trial (DEW-IT). Hypertension. 2002; 40: 612-8.

[29] Goodpaster BH, Delany JP, Otto AD, et al. Effects of diet and physical activity interventions on weight loss and cardiometabolic risk factors in severely obese adults: a randomized trial. J Am Med Assoc 2010; 304: 1795-802.
[30] Azadbakht L, Mirmiran P, Esmaillzadeh A, Azizi F. Better dietary adherence and weight maintenance achieved by a long-term moderate-fat diet. Br J Nutr 2007; 97: 399-404.

[31] Kochar J, Djoussé L, Gaziano JM. Breakfast cereals and risk of type 2 diabetes in the physicians' health study I. Obes Res 2007; 15: $3039-44$

[32] Svetkey LP, Simons-Morton D, Vollmer WM, et al. Effects of dietary patterns on blood pressure: subgroup analysis of the Dietary Approaches to Stop Hypertension (DASH) randomized clinical trial. Arch Int Med 1999; 159: 285-93.

[33] Stamler J, Caggiula AW, Grandits GA. Relation of body mass and alcohol, nutrient fiber and caffeine intakes to blood pressure in the special intervention and usual care groups in the Multiple Risk Factor Intervention Trial. Am J Clin Nutr 1997; 65: 338S-65S.

[34] Lotito SB, Frei B. The increase in human plasma antioxidant capacity after apple consumption is due to the metabolic effect of fructose on urate, not apple-derived antioxidant flavonoids. Free Radic Biol Med 2004; 37: 251-8.

[35] Johnson RJ, Rideout BA. Uric acid and diet - Insight into the epidemic of cardiovascular disease. N Engl J Med 2004; 350: 1071-3.

[36] Stone NJ, Kushner R. Effects of dietary modification and treatment of obesity. Med Clin North Am 2000; 84: 95-122.

[37] Ebbeling CB, Leidig MM, Feldman HA, Lovesky MM, Ludwig DS. Effects of a low-glycemic load vs low-fat diet in obese young adults. J Am Med Assoc 2007; 297: 2092-102.

[38] Katan MB, Grundy SM, Willett WC. Should a low-fat, highcarbohydrate diet be recommended for everyone? Beyond low-fat diets. N Engl J Med 1997; 337: 563-6.

\section{(C) Håglin et al.; Licensee Bentham Open}

This is an open access article licensed under the terms of the Creative Commons Attribution Non-Commercial License (http://creativecommons.org/licenses/by-nc/3.0/) which permits unrestricted, non-commercial use, distribution and reproduction in any medium, provided the work is properly cited. 